\title{
Trace Element Soil Quality Status of Mt. Cameroon Soils
}

\author{
Veronica E. Manga, ${ }^{1}$ Christopher M. Agyingi, ${ }^{2}$ and Cheo E. Suh ${ }^{2}$ \\ ${ }^{1}$ Department of Environmental Science, University of Buea, Buea, Cameroon \\ ${ }^{2}$ Department of Geology, University of Buea, Buea, Cameroon
}

Correspondence should be addressed to Veronica E. Manga; ebotmangav@gmail.com

Received 15 April 2014; Revised 27 August 2014; Accepted 8 September 2014; Published 23 September 2014

Academic Editor: Wayne Stephenson

Copyright (C) 2014 Veronica E. Manga et al. This is an open access article distributed under the Creative Commons Attribution License, which permits unrestricted use, distribution, and reproduction in any medium, provided the original work is properly cited.

\begin{abstract}
The concentrations of $\mathrm{Cu}, \mathrm{Co}, \mathrm{Zn}, \mathrm{Ni}, \mathrm{V}$, and $\mathrm{Cr}$ in topsoils at six sites located along the lower slopes of Mt. Cameroon were assessed for their potential toxicity to humans and the ecosystem. Soils were collected from horizons down to a depth of $70 \mathrm{~cm}$ and analysed for trace element concentration by ICP-MS technique. The Dutch soil quality standards which use \%clay/silt and organic matter content to derive target values were used to assess the contamination levels of the soils. The content of these soils was also compared to the United Kingdom ICRCL "soil trigger" values. Zinc and $\mathrm{Cu}$ values were persistently below the normal value (A) and occurred in the lower elevation, the region of extreme weathering, while $\mathrm{Cr}$ and $\mathrm{V}$ values were above the intervention $(\mathrm{C})$ values. The high content of $\mathrm{Cr}$ in common fertilisers poses a potential risk in toxicity in the higher elevations experiencing lower weathering rates, where soil Cr levels are elevated.
\end{abstract}

\section{Introduction}

Many trace elements are essential macro- and micronutrients for humans, plant growth, and the maintenance of healthy ecosystems. Micronutrients like $\mathrm{Cu}, \mathrm{Mn}$, Se, and $\mathrm{Zn}$ can be toxic at high concentrations in the soil. Trace elements unknown to be essential to plant growth, such as barium $(\mathrm{Ba})$, cadmium $(\mathrm{Cd})$, chromium $(\mathrm{Cr})$, lead $(\mathrm{Pb})$, and nickel $(\mathrm{Ni})$, are toxic at high concentrations or under certain environmental conditions in soils. One of the major factors controlling soil trace element content is the parent rock material. Soils vary across landscapes and rock weathering and other soil-forming processes may result in the addition or removal of these elements from the soil. High background concentrations of trace elements, whether from natural or anthropogenic sources, could result in mobilization and release into surface and subsurface waters and subsequently incorporation into the food chain. Soil factors such as organic matter, type and amount of clay, $\mathrm{pH}$, and cation exchange capacity (CEC) influence the quantity of trace elements available for mobilization and release or sorption in a soil [1].

Regulations to protect humans and the environment from toxicities and deficiencies related to trace elements are primarily based on soil quality reference values which are being developed in many countries. Many countries that have not developed their own formal guidelines follow the "Dutch standard" to support decision-making in assessing and monitoring soil quality. The Dutch are improving their soil quality in light of new scientific work particularly with regard to the impact of listed substances on living species and ecosystems [2]. Two values are particularly important in decision-making in regulating trace metals in soils. These are the target value (the $A$-value, the normal or natural level) and the intervention value (the $C$-value the clean-up level) [3]. Cameroon has not started working on soil standards; consequently, any level of information that can serve as indicators remains of immense importance in the fertile areas of Mt. Cameroon for reasons such as (i) identification of particular elements for further research on TE (trace elements) and health and (ii) identification of target soils (spatial) for further studies. The present study examines the potential risks associated with selected trace elements in the Mt. Cameroon region. The bulk concentration of selected trace metals $(\mathrm{Cu}, \mathrm{Co}, \mathrm{Cr}, \mathrm{Ni}, \mathrm{Zn}$, and $\mathrm{Pb})$ in surface soils in $\mathrm{Mt}$. Cameroon is compared with world averages, ICRCL (UK) "trigger" values for open space, and the Dutch standard for assessing soil contamination. 


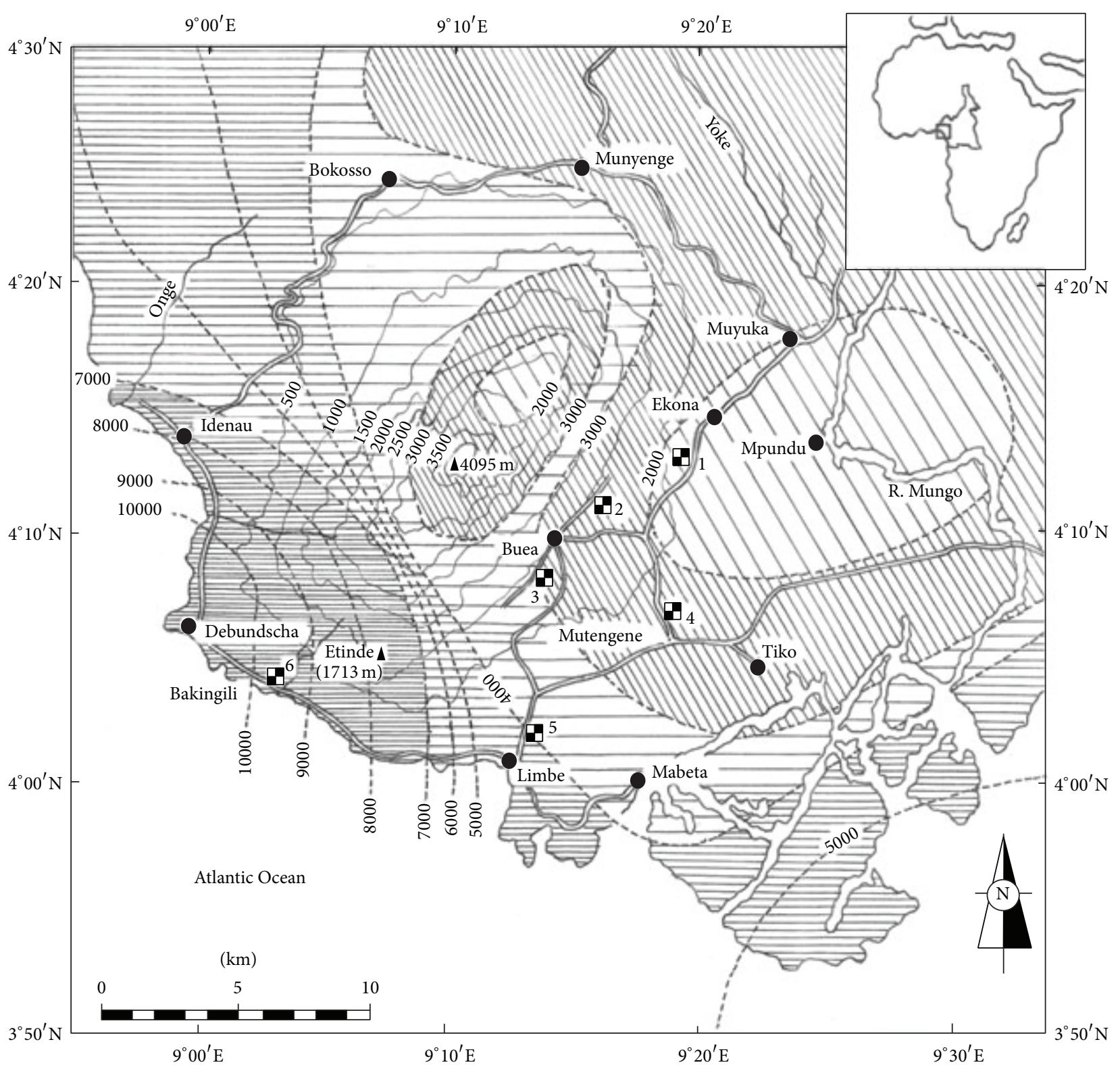

\begin{tabular}{|c|c|c|c|}
\hline 1000 & Contour & Study sites: & Annual average rainfall \\
\hline & Isohyet & & \multirow{6}{*}{$\begin{array}{l}0-2000 \mathrm{~mm} \\
2001-3000 \mathrm{~mm} \\
3001-4000 \mathrm{~mm} \\
4001-7000 \mathrm{~mm} \\
7001-11000 \mathrm{~mm}\end{array}$} \\
\hline$y$ & River/stream & $\begin{array}{l}1 \text { EKA } \\
2 \text { BUA }\end{array}$ & \\
\hline \begin{tabular}{|l|}
$\bullet$ \\
\end{tabular} & Major settlements & $3 \mathrm{BOR}$ & \\
\hline \begin{tabular}{|l|l|l}
$\mathbf{A}$ & \\
\end{tabular} & Mountain peak & 4 MUT & \\
\hline 田 & Study site & $5 \mathrm{LBE}$ & \\
\hline & & & \\
\hline
\end{tabular}

Figure 1: Map of Mt. Cameroon region showing the various sampling sites, elevation, and isohyets [23].

\section{Materials and Methods}

2.1. Study Area. The study area lies on the lower slopes of the south-southeastern flank of Mt. Cameroon volcano, which is located within latitudes $4^{\circ} 000-4^{\circ} 130 \mathrm{~N}$ and longitudes $9^{\circ} 000-9^{\circ} 300 \mathrm{E}$ (Figure 1). Mt. Cameroon belongs to the Cameroon volcanic line (CVL), an intraplate volcanic alignment extending from the Gulf of Guinea into the African continent. The flanks of the volcano are dominated by cones, some of which are breached due to lava effusion. The plain located to the east of the volcano consists of post-Cretaceous sediments and Quaternary alluvium (Figure 1). The climate 
of the SSE slopes of Mt. Cameroon is humid tropical one, characterized by a pronounced dry season (mid-November to March) and wet season (mid-March to November) [4]. The combination of high relief $(4095 \mathrm{~m})$ and proximity of the sea leads to strong local climatic contrasts. Mean annual temperatures decrease from 26 to $29^{\circ} \mathrm{C}$ at sea level to $0^{\circ} \mathrm{C}$ at the top of the edifice, and this large temperature drop is associated with a decrease in rainfall. Extremely high rainfall is recorded on the southwestern flank where it can reach $12,000 \mathrm{~mm}$ /year. Lower rainfall occurs on the southeastern flank because it is partially sheltered from oceanic influence (e.g., $1800 \mathrm{~mm} /$ year at Ekona).

Mt. Cameroon soils are formed from lavas, pyroclastic flows, and lahars transported as mudflows from the top of the volcano. Several authors (e.g., Fitton et al. [5] and Suh et al. [6]) report the bulk-rock composition of the rocks of Mt. Cameroon to fall within the TAS (total alkalis versus silica) field of basalt, basanite-trachybasalt, phonotephrite, and basaltic trachyandesite. These studies also report that Mt. Cameroon magmas are of intraplate-type, with characteristically high concentrations of the high-field-strength elements $\mathrm{Ti}, \mathrm{Nb}$, and $\mathrm{Ta}[6]$. The primary minerals are mainly plagioclase (dominance of anorthite over albite) and ferromagnesian minerals (pyroxene (mainly augite), olivine, and iddingsite).

The present study extends our previous work on the behaviour of elements during rock weathering in six soil profiles located at different elevations along the SSE slopes of Mt. Cameroon [7]. These soil profiles are found at elevations of $1017 \mathrm{~m}$ at Buea (BUA), $944 \mathrm{~m}$ at Borstal (BOR), $458 \mathrm{~m}$ at Ekona (EKA), $298 \mathrm{~m}$ at Mutengene (MUT), $84 \mathrm{~m}$ at Limbe (LBE), and $30 \mathrm{~m}$ at Bakingili (BAK). At these elevations, the environmental factors are judged to be different with MAP values decreasing with elevations from $>8,000$ to $3,000 \mathrm{~mm}$. These soil profiles were developed from the alteration of pyroclastic deposits in the deepest units of the profiles.

2.2. Soil Sampling and Analysis. Top soils developed on basaltic rocks representing different stages of soil development were sampled from six sites including Buea town, Mutengene, Limbe, Ekona, Bakingili, and Borstal denoted as BUA, MUT, LBE, EKA, BAK, and BOR, respectively, throughout the text. A total of eleven disturbed soil samples were collected from the soil horizons up to a depth of $70 \mathrm{~cm}$. The samples were air-dried for over $12 \mathrm{hrs}$ and stored in plastic bags. Roots and litter were removed and samples lightly crushed with fingers and in a ceramic mortar and pestle to loosen soil aggregates. Samples were then weighed and adequately mixed, quartered, and stored in plastic bags in plastic sample boxes. All samples were air-dried and sieved through a $2 \mathrm{~mm}$ sieve and routine analysis was run on the fine fraction.

Eleven processed soil samples (including two duplicates) of about $15 \mathrm{mg}$ ( $<2 \mathrm{~mm}$ fraction) were shipped to Acme Laboratory, Ontario, Canada, for routine geochemical analysis of trace elements: $\mathrm{Cu}, \mathrm{Co}, \mathrm{Cr}, \mathrm{Ni}, \mathrm{Zn}, \mathrm{Pb}$, and $\mathrm{V}$. An aliquot of each horizon was analyzed by inductively coupled plasma atomic emission spectrometry (ICP-AES) following a lithium metaborate/tetraborate fusion acid digestion which ensured that the entire sample was dissolved, thus making it possible to solubilize the trace and major oxides including $\mathrm{SiO}_{2}$. Total carbon (analysed by Acme Laboratory, Canada) was determined by infrared adsorption using Leco CS200 after igniting at $>1650^{\circ} \mathrm{C}$. The results are attributed to the mineralisation of organic matter since the parent material does not contain carbonate minerals. Organic matter was calculated as $\%$ organic matter $=1.7 \times \%$ organic carbon. All eleven processed soil samples ( $<2 \mathrm{~mm}$ fraction) were sent to the Soil Laboratory, University of Dschang, Cameroon, for physicochemical analysis. Particle-size distribution was determined by dry sieving and the pipette method. After shaking with a dispersing agent, sand was fractionated by dry sieving and the clay and silt fractions were fractionated by the pipette method [8]. Measurements of $\mathrm{pH}$ were made in water and in $1 \mathrm{M} \mathrm{KCl}$ in a $1: 2.5$ soil: water suspension. Cation exchange capacity (CEC) was determined using the ammonium acetate method [8].

2.3. Calculations. There is no uniform procedure for setting contamination thresholds for heavy metals in soils. This complexity arises from several factors; that is, different metal origins and different metal species will not be equally mobile or bioavailable and the intended use of the site may require different levels of concentration. Adsorption of metals is generally acknowledged to be directly proportional to soil $\mathrm{pH}$ and this has been observed for various adsorbing soil components and differing soil types [9]. Threshold concentrations are generally given for specific conditions, commonly $\mathrm{pH}$.

In the United Kingdom, the Interdepartmental Committee on the Redevelopment of Contaminated Land [10] trigger concentrations of metals in contaminated soils have been the guide to acceptable threshold levels for those posing a hazard to human health, such as $\mathrm{As}, \mathrm{Cd}, \mathrm{Cr}, \mathrm{Pb}, \mathrm{Hg}$, and $\mathrm{Se}$, and those that may be phytotoxic but are not normally hazardous to humans, such as $\mathrm{B}, \mathrm{Cu}, \mathrm{Ni}$, and $\mathrm{Zn}[10]$.

The Dutch standard for soil contamination is based on two values which are particularly important in making decisions on the regulation of heavy metals in soils. These are the target value (the $A$-value, the normal or natural level) and the intervention value (the $C$-value, the clean-up level) [3]. Soil assessment for the derivation of these values considers two major soil parameters, \%clay/silt and organic matter content.

\section{Results and Discussion}

Results of soil physical properties and trace element concentration are shown in Table 1. BAK has the highest content of organic matter followed by BOR. The soils are generally acidic with $\mathrm{BOR}$ being the most acidic with a $\mathrm{pH}$ of $\sim 3.88$. EKA the most weathered soil [7] has the highest clay content followed by BUA. Trace element concentration is ranked as follows: $\mathrm{Cr}$ $>\mathrm{V}>\mathrm{Zn}>\mathrm{Cu}>\mathrm{Co}>\mathrm{Ni}>\mathrm{Pb}$. The high concentrations of $\mathrm{Cr}$ and $\mathrm{V}$ can be attributed to the basaltic composition of the parent rock. Sato et al. [11] and Che et al. [12] measured high $\mathrm{Ni}, \mathrm{Cr}$, and $\mathrm{V}$ concentrations in some picritic rocks samples 


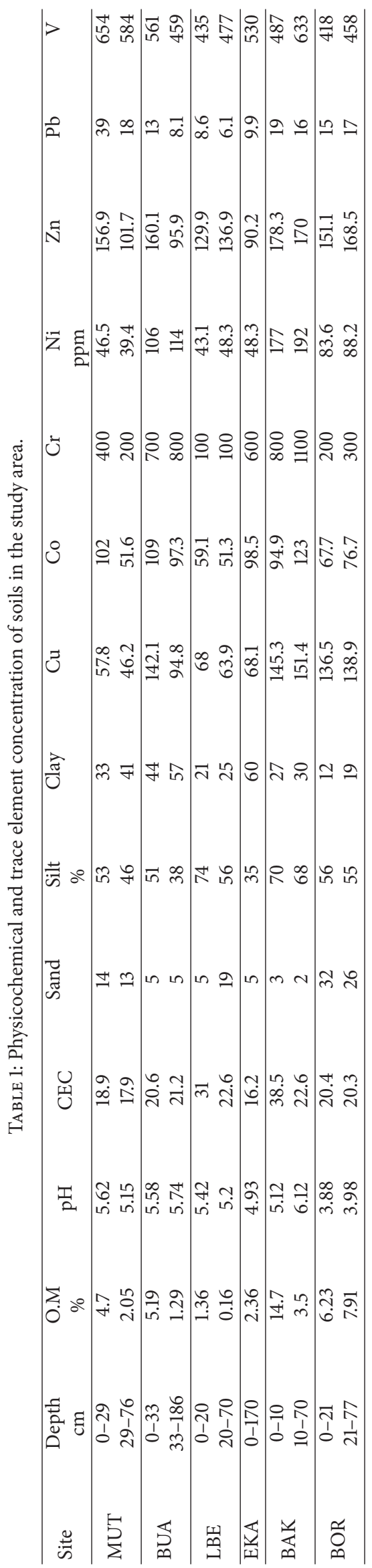


TABLE 2: Trace metal concentration in Mt. Cameroon soils compared to mean values for soils worldwide, ICRCL (UK) soil "trigger" concentrations (ppm).

\begin{tabular}{lccc}
\hline Element & Av. soil conc. ${ }^{\text {a }}$ & ICRCL (UK) soil “trigger”b $^{\text {"b }}$ & Soil conc. Mt. Cameroon $^{c}$ \\
\hline $\mathrm{Cu}$ & 24 & 50 & $46-145$ \\
$\mathrm{Co}$ & 30 & $\mathrm{Na}$ & $67-101$ \\
$\mathrm{Cr}$ & 67 & 1000 & $100-800$ \\
$\mathrm{Ni}$ & 24 & 70 & $39-203$ \\
$\mathrm{Zn}$ & 67 & 300 & $68-178$ \\
$\mathrm{~Pb}$ & 29 & 2000 & $5.3-39$ \\
$\mathrm{~V}$ & 100 & - & $418-654$ \\
\hline
\end{tabular}

(i) ${ }^{a}$ Kabata-Pendias and Pendias [24].

(ii) ${ }^{b}$ Interdepartmental Committee on the Redevelopment of Contaminated Land [10].

(iii) ${ }^{\mathrm{c}}$ Surface soil concentration.

from the Mt. Cameroon region. Basalts are enriched in $\mathrm{Fe}$ family elements (i.e., $\mathrm{Ti}, \mathrm{V}, \mathrm{Co}$, and $\mathrm{Ni}$ ), which are conserved during soil formation due to the preferential loss of more mobile major elements. Zhang et al. [13] observed an increase of $\mathrm{Ti}, \mathrm{V}$, and $\mathrm{Cr}$ with soil age, which in this case can be inferred from the weathering intensity, particularly in the most weathered profiles EKA and BUA. Che et al. [12] made similar observations for $\mathrm{V}$ and $\mathrm{Cr}$ in this area. The influence of weathering in the distribution of the Fe-family elements $(\mathrm{Co}, \mathrm{Cu}, \mathrm{Cr}$, and $\mathrm{Ni})$ is evident in BUA and BAK profiles. In the former, enrichment is associated with secondary mineral formation and the removal of more mobile elements while predominantly organic matter sequestration may account for the latter. The lower concentrations of these elements in the most weathered soil profiles, EKA and BUA, could explain leaching under excessive weathering [7]. In the low to moderately weathered profiles, MUT and LBE, these elements could be distributed predominantly in primary (particularly BOR) and secondary mineral phases or they may have been mobilised out of the soils due to the higher leaching conditions that exist in the lower altitudes. Zinc on the other hand is higher in the moderately weathered soils, MUT and LBE. The concentration of trace elements is compared worldwide and to ICRCL (UK) trigger values in Table 2.

Cobalt concentration varies from $\sim 40$ to $135 \mathrm{ppm}$. BAK, $\mathrm{BUA}$, and BOR have the highest values. Cobalt concentrations for the topsoil samples are well below the intervention values and above the target values (Table 3 ). The geochemical behaviour of cobalt generally follows that of the iron-manganese system and its concentration in sediment and soil systems is mainly controlled by adsorption and coprecipitation reactions with manganese and iron oxide minerals [14].

Copper concentration in the soils varies between 46 and $145 \mathrm{ppm}$. Compared to the ICRCL (UK) values (Table 2), some soils are above the trigger values. The results show the highest concentrations in BAK, BOR, and BUA which are likely in the form of $\mathrm{Cu}(\mathrm{II})$ and are bounded to fulvic acids [15]. Temminghoff et al. [16] reported that, at $\mathrm{pH} 6.6,>99 \%$ of $\mathrm{Cu}$ in soil solution was predicted by models to be bound to dissolved organic matter, decreasing to $30 \%$ at $\mathrm{pH}$ 3.9. In this study, soil $\mathrm{pH}$ values were as low as 3.89 , implying acidic conditions which according to such predictive models could enhance the release of $\mathrm{Cu}$ ions from organic complexing chelates. Copper concentrations are below the intervention values indicating that these soils are not contaminated. However, some soils are below the target values (MUT and EKA) required for their proper functioning.

Zinc concentrations vary from about 68 to $178 \mathrm{ppm}$. The highest concentrations are found at MUT, LBE, BAK, and $\mathrm{BOR} . \mathrm{Zn}$ is likely associated with organic matter and $\mathrm{Mn}-\mathrm{Fe}$ oxides. The concentration of $\mathrm{Zn}$ is below the ICRCL threshold value (Table 2). BUA and EKA soils show concentration values below the target values which are required for the proper functioning of soils (Table 3). Zinc is an essential plant nutrient especially for maize [17]. Zinc together with $\mathrm{Cu}$ is important in the production of animal feed because of their multifunctional role in the metabolism of animals [18]. Zinc deficiency is known to occur in the same soils where there is the greatest risk of $\mathrm{Cu}$ deficiency [17]. This condition is found in the EKA soils.

Chromium concentration varies from 800 to $100 \mathrm{ppm}$ with an average of $400 \mathrm{ppm}$. Cr content is below the ICRCL trigger value. In BUA and BAK $\mathrm{Cr}$ content exceeds intervention values, inferring the possibility of contamination (Table 3). Although $\mathrm{Cr}$ is an essential micronutrient for animals, its role in plants has not been established. The chemical speciation of trace elements in the rhizosphere profoundly affects their solubility, mobility, and toxicity. In soils, $\mathrm{Cr}$ that is present in the +6 oxidation state $(\mathrm{Cr}(\mathrm{VI}))$ is more mobile, more readily bioaccumulated, and 100 to 1000 times more toxic when present in the +3 oxidation state $(\mathrm{Cr}(\mathrm{III}))$ [19]. Nickel concentration varies from 39 to $203 \mathrm{ppm}$. The highest concentrations are found in BUA and BAK. Compared to the ICRCL threshold, soils in BUA, BAK, and BOR can be potentially polluted. The concentrations of $\mathrm{Ni}$ in all the surface soils are well below the intervention values (Table 3 ), indicating the absence of contamination. With reference to the target values, EKA contents are below those required for proper soil functioning. Nickel is an essential micronutrient and has been shown to influence seed germination. The results show that $\mathrm{Ni}$ is comparatively highly mobile when compared to, for instance, $\mathrm{Zn}$ and $\mathrm{Cu}$. This therefore can be of a higher risk to contamination of water resources. 


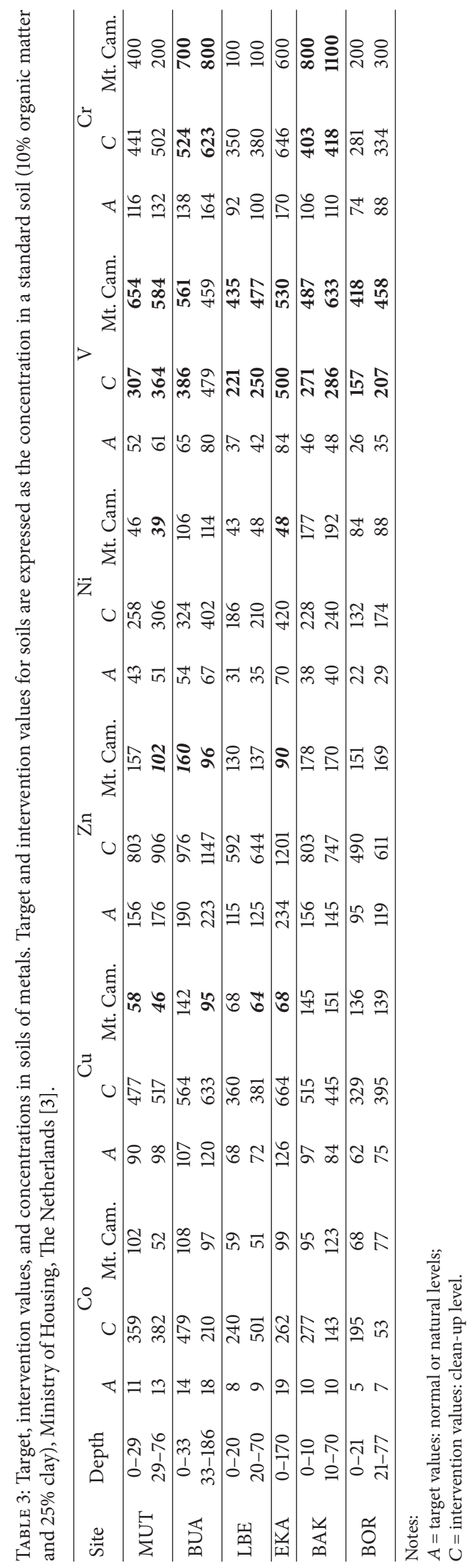


TABLE 4: Heavy metal concentration $\left(\mathrm{mg} \mathrm{kg}^{-1}\right)$ in common fertilizer constituents concentration [25].

\begin{tabular}{lccc}
\hline Element & Phosphate & Potassium & Farmyard \\
\hline $\mathrm{Cd}$ & $9-30$ & $7-15$ & $0.3-1.8$ \\
$\mathrm{Cr}(\mathrm{T})$ & 1000 & 1000 & 12 \\
$\mathrm{Ni}$ & 300 & 80 & 17 \\
$\mathrm{Zn}$ & $5-1450$ & - & $15-250$ \\
\hline
\end{tabular}

Lead concentration varies from 5.3 to $39 \mathrm{ppm}$. Lead accumulations arising from atmospheric deposition are highest in MUT, BAK, and BOR. Lead in these profiles is principally associated with organic matter. Present lead values in all profiles are exceedingly below those of the threshold. Atmospheric deposition of $\mathrm{Pb}$ linked to inputs from Saharan dust in this region at rates of up to $8 \%$ has been reported by Dia et al. [20]. In EKA it is possible that atmospheric $\mathrm{Pb}$ is mobilized as $\mathrm{Pb}-\mathrm{P}$. Vanadium in these soils exhibits very low mobility and as a consequence shows very high concentration in soils. The contents are consistently above the intervention values (Table 3). $\mathrm{V}$ is described as a new essential trace micronutrient in animal nutrition by Poulsen [21].

Intensive agricultural usage of these soils, for example, for plantation (palm, banana, and tea) and food cropping, requires large inputs of pesticides, fertilizers $(\mathrm{N}, \mathrm{P}$, and $\mathrm{K})$, and micronutrients. These practices also provide another potential source of trace element contamination, that is, from impurities in commercial fertilisers. Fergusson [22] considers that the primary sources of $\mathrm{Cd}, \mathrm{Pb}$, and $\mathrm{As}$ that may contaminate soils are phosphate fertilisers. Table 4 shows heavy metal concentrations in some common fertiliser constituents. Considering that the $\mathrm{Cr}$ content is already high, the application of inputs with high Cr content can potentially contaminate the soil. Chromium is easily absorbed from the soil by corn, a crop that is intensively cultivated in this area of Cameroon, which means that our food supply is at risk of contamination if high Cr-inputs are used.

\section{Conclusion}

The concentrations of these elements in soils generally reflect those of the parent material, with the exception of $\mathrm{Pb}$. Distribution of the latter is associated with anthropogenic activities particularly traffic. Potential soil deficiency is associated with highly mobile elements, that is, $\mathrm{Zn}$ and $\mathrm{Ni}$, and is displayed in the most weathered soil, EKA. Cu deficiency is associated with soils under extreme leaching conditions, that is, MUT and LBE, located in the lower elevations with higher rainfall. $\mathrm{Cr}$ and $\mathrm{V}$ contents display some levels of contamination. The high content of $\mathrm{Cr}$ in common fertilisers may pose a potential risk in toxicity in the higher elevations where soil Cr levels are elevated.

\section{Conflict of Interests}

The authors declare that there is no conflict of interests regarding the publication of this paper.

\section{References}

[1] A. Slagle, J. Skousen, D. Bhumbla, J. Sencindiver, and L. McDonald, "Trace element concentrations of three soils in central appalachia," Soil Survey Horizons, vol. 45, no. 3, pp. 7385,2004 .

[2] P. R. J. Danneman and J. G. Robberse, "Ecotoxicological risks assessment as a base for development of soil quality criteria," in Contaminated Soil '90, F. Arendt, H. Hinsenfelt, and W. J. van den Brink, Eds., pp. 157-164, Kluwer Academic Publisher, Dordrecht, The Netherlands, 1990.

[3] Ministry of Housing Netherland, "Physical planning and environmental conservation," Report HSE 94.021, 1994.

[4] G. W. van Barneveld, "Agroclimatic conditions of West Africa and Cameroon," in Proceedings of the 3rd International Forum on Soil Taxonomy and Agro-Technology Transfer, H. Ikawa and G. Y. Tsuji, Eds., Benchmark Soils Project Technical Report 10, pp. 121-133, University of Hawaii, 1987.

[5] J. G. Fitton, C. R. J. Kilburn, M. F. Thirlwall, and D. J. Hughes, "1982 eruption of Mount Cameroon, West Africa," Nature, vol. 306, no. 5941, pp. 327-332, 1983.

[6] C. E. Suh, R. S. J. Sparks, J. G. Fitton et al., "The 1999 and 2000 eruptions of Mount Cameroon: eruption behaviour and petrochemistry of lava," Bulletin of Volcanology, vol. 65, no. 4, pp. 267-281, 2003.

[7] V. E. Manga, C. E. Suh, C. M. Agyingi, and E. M. Shemang, "Mineralogy and geochemistry of soils developed along the slopes of Mt. Cameroon, West Africa," Journal of African Earth Sciences, vol. 81, pp. 82-93, 2013.

[8] USDA-NRCS, "Soil survey laboratory methods manual," Soil Survey Investigations Report 42, Version 3.0. USDA-NRCSNational Soil Survey Centre, Washington, DC, USA, 1996.

[9] B. J. Alloway, I. Thornton, G. A. Smart, J. C. Sherlock, and M. J. Quinn, "Metal availability," Science of the Total Environment, vol. 75, no. 1, pp. 41-69, 1988.

[10] Interdepartmental Committee on the Redevelopment of Contaminated Land, ICRCL 59/83 Guidance on the Assessment and Redevelopment of Contaminated Land, Code EPTSSP187-5RH3, CEDP/EPTS, Romney House, London, UK, 2nd edition, 1987.

[11] H. Sato, S. Aramaki, M. Kusakabe et al., "Geochemical difference of basalts between polygenetic and monogenetic volcanoes in the central part of the Cameroon volcanic line," Geochemical Journal, vol. 24, no. 6, pp. 357-370, 1990.

[12] V. B. Che, K. Fontijn, G. G. J. Ernst et al., "Evaluating the degree of weathering in landslide-prone soils in the humid tropics: the case of Limbe, SW Cameroon," Geoderma, vol. 170, pp. 378-389, 2012.

[13] G.-L. Zhang, J.-H. Pan, C.-M. Huang, and Z.-T. Gong, "Geochemical features of a soil chronosequence developed on basalt in Hainan Island, China," Revista Mexicana de Ciencias Geológicas, vol. 24, no. 2, pp. 261-269, 2007. 
[14] J. D. Hem, C. E. Roberson, and C. J. Lind, "Study and interpretation of the chemical characteristics of natural water," U.S. Geological Survey Water Supply Paper 2254, US Geological Survey, Alexandria, Va, USA, 1985.

[15] G. Sposito, The Chemistry of Soils, Oxford University Press, USA, 1989.

[16] E. J. M. Temminghoff, S. E. A. T. M. van der Zee, and F. A. M. de Haan, "Copper mobility in a copper-contaminated sandy soil as affected by $\mathrm{pH}$ and solid and dissolved organic matter," Environmental Science and Technology, vol. 31, no. 4, pp. 11091115, 1997.

[17] L. Knudsen, "Status of micronutrient demand of Danish crops," in Essential Trace Elements for Plants, Animals and Humans, G. Thorvaldsson and R. S. Jónsdóttir, Eds., NFJ Seminar no. 370, Reykjavík, Iceland, August 2005.

[18] M. Korhonen, M. Rinne, and P. Huhtanen, "Effects of soil characteristics and fertiliser application on grass yield and chemical composition including mineral and trace element contentfarm scale studies in Finland 1995-2004," in Essential Trace Elements for Plants, Animals and Humans, G. Thorvaldsson and R. S. Jónsdóttir, Eds., NFJ Seminar no. 370, Reykjavík, Iceland, August 2005.

[19] F.-Y. Wu, W.-Y. Wu, H.-W. Kuo, C.-S. Liu, R.-Y. Wang, and J.S. Lai, "Effect of genotoxic exposure to chromium among electroplating workers in Taiwan," Science of the Total Environment, vol. 279, no. 1-3, pp. 21-28, 2001.

[20] A. Dia, C. Chauvel, M. Bulourde, and M. Gérard, "Eolian contribution to soils on Mount Cameroon: isotopic and trace element records," Chemical Geology, vol. 226, no. 3-4, pp. 232$252,2006$.

[21] H. D. Poulsen, "Trace elements in animal nutrition," in Essential Trace Elements for Plants, Animals and Humans, G. Thorvaldsson and R. S. Jónsdóttir, Eds., NFJ Seminar no. 370, Agricultural University of Iceland, Reykjavík, Iceland, 2005.

[22] J. E. Fergusson, The Heavy Elements: Chemistry, Environmental Impacts and Health Effects, Pergamon Press, New York, NY, USA, 1990.

[23] M. F. Benedetti, A. Dia, J. Riotte et al., "Chemical weathering of basaltic lava flows undergoing extreme climatic conditions: the water geochemistry record," Chemical Geology, vol. 201, no. 1-2, pp. 1-17, 2003.

[24] A. Kabata-Pendias and H. Pendias, Trace Elements in Soils and Plants, CRC Press, Boca Raton, Fla, USA, 3rd edition, 2001.

[25] B. Alloway, Ed., Heavy Metals in Soils, Blackie Academic and Professional, Chapman and Hall, London, UK, 1995. 

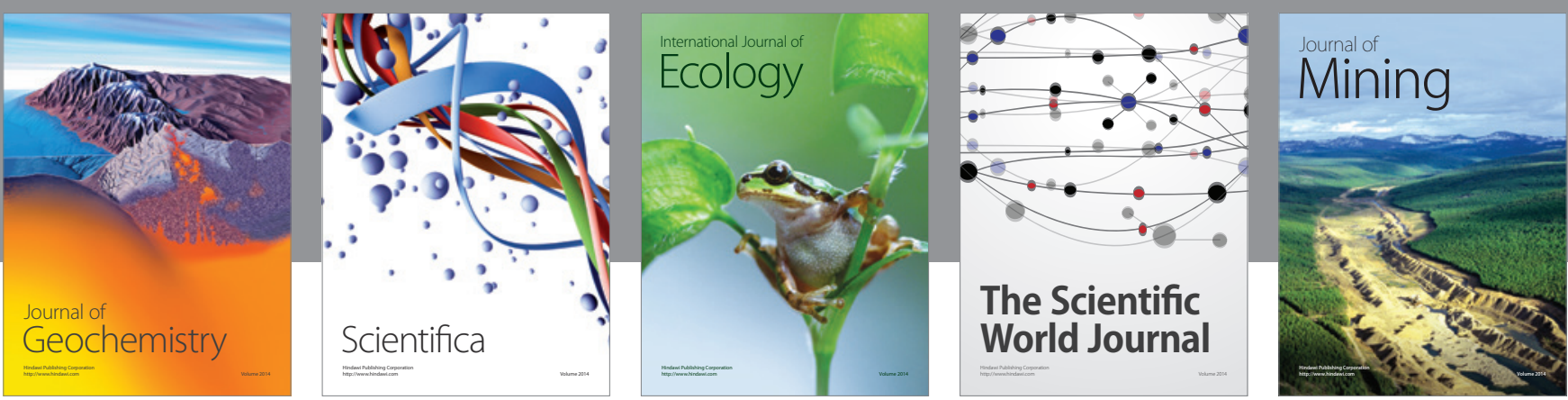

The Scientific World Journal
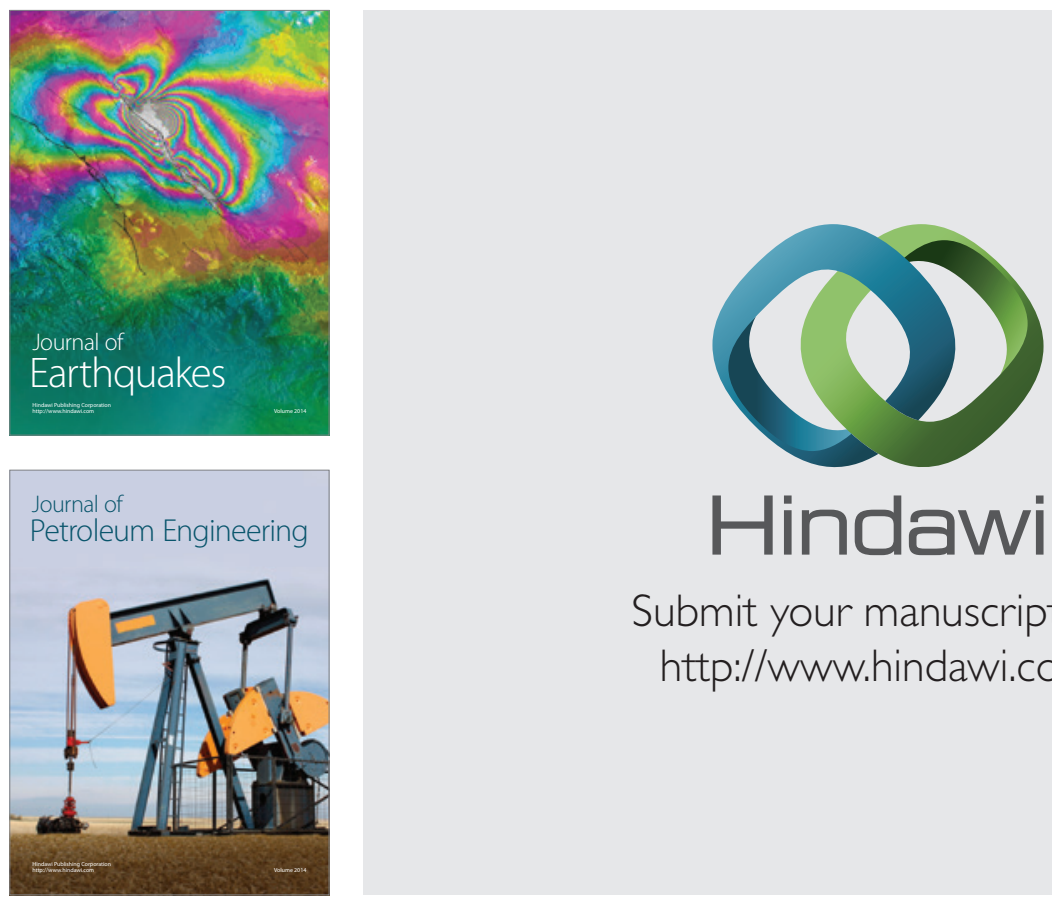

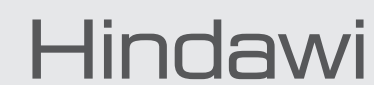

Submit your manuscripts at

http://www.hindawi.com
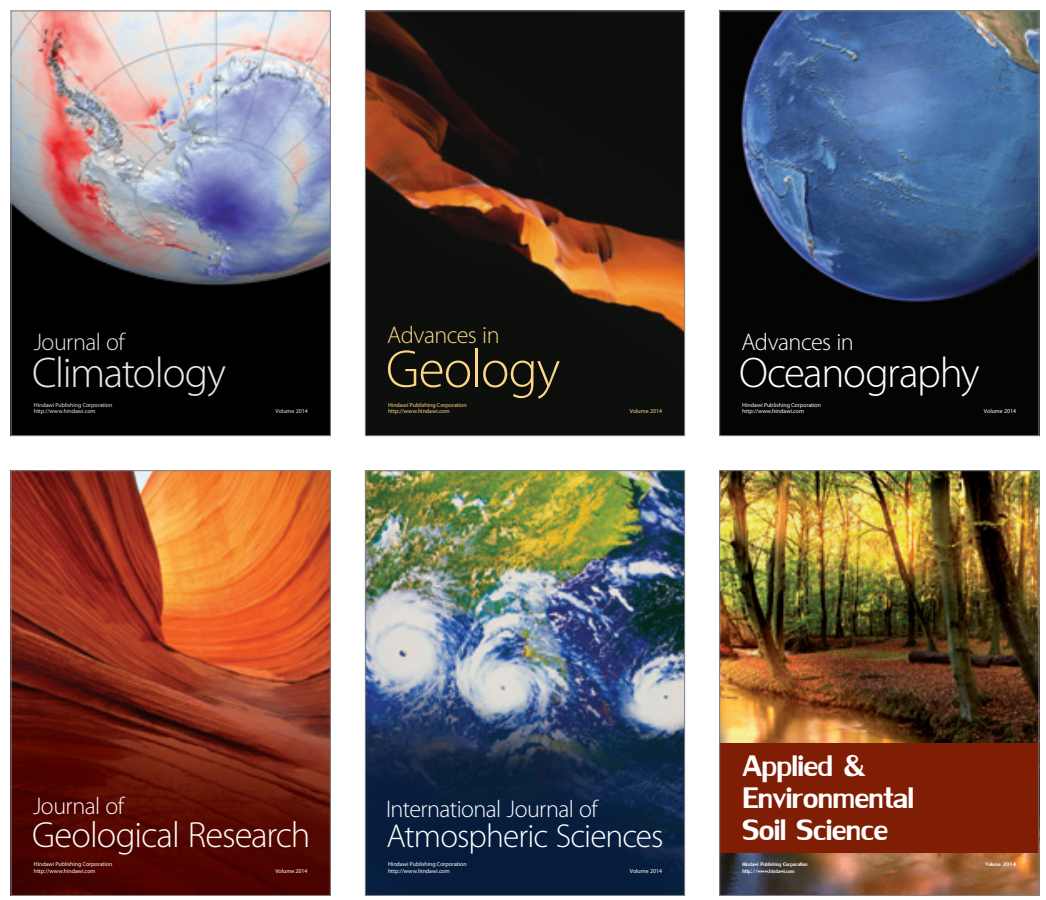
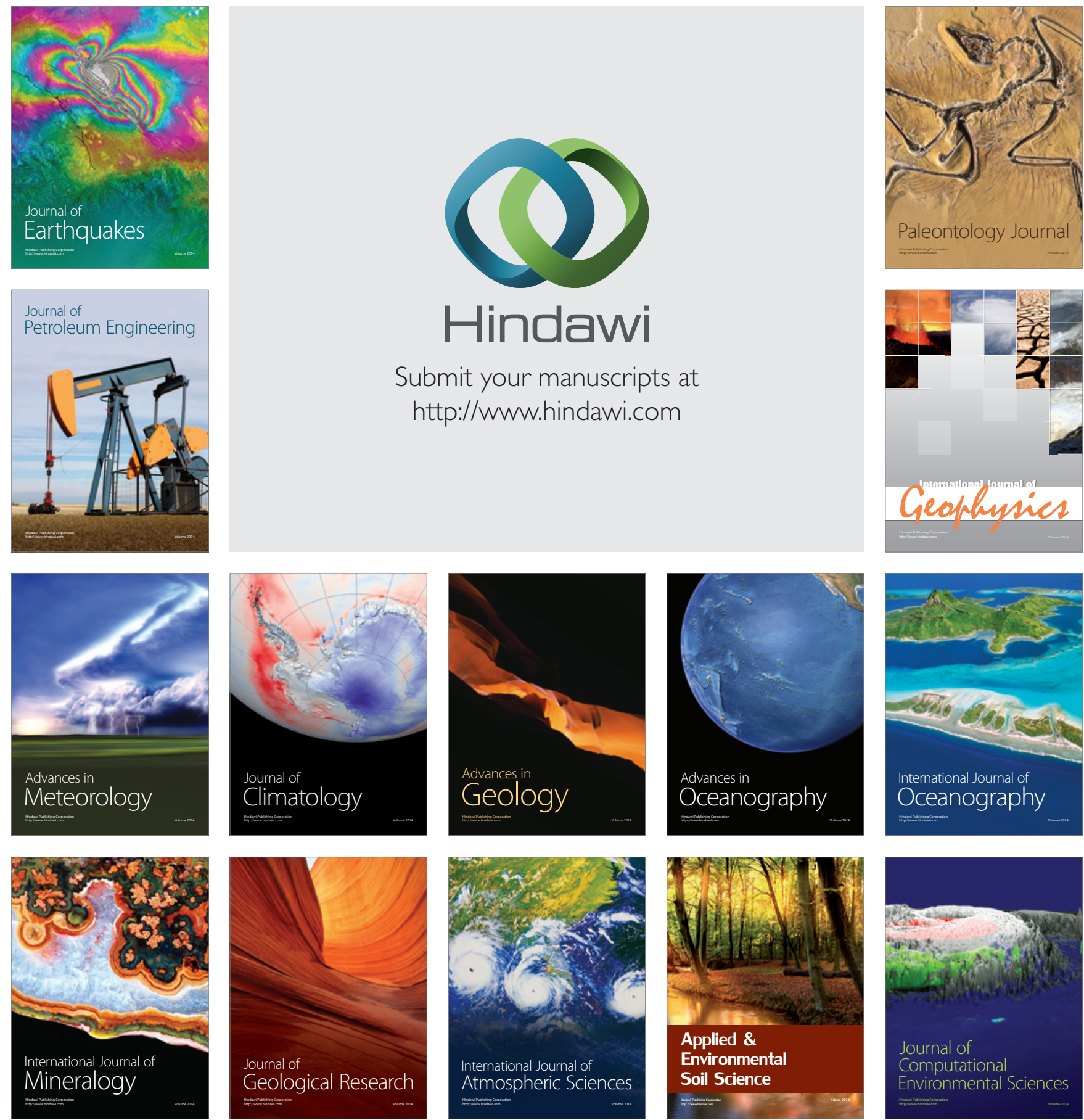